\title{
Phytosterol Screening of Skin and Seed Extracts of Wild Grape Ampelocissus martinii Planch
}

\author{
WILAIWAN SIMCHUER and PRASONG SRIHANAM* \\ Creative Chemistry and Innovation Research Unit, the Center of Excellence in Chemistry, \\ Department of Chemistry, Faculty of Science, Mahasarakham University, Kantarawichai, \\ Maha Sarakham 44150, Thailand. \\ ${ }^{*}$ Corresponding author E-mail: prasong.s@msu.ac.th \\ http://dx.doi.org/10.13005/ojc/340235
}

(Received: October 29, 2017; Accepted: January 05, 2018)

\begin{abstract}
Reports on phytosterol in wild grape, Ampelocissus martinii Planch fruits are rarely available world wide. We have investigated the total triterpenoid content (TTC) and total sterol content (TSC) in skin and seed extracts from different growth stages of wild grape fruits using a spectrophotometric assay. In addition, we analyzed some free sterols using high performance liquid chromatography (HPLC). The mature fruit showed the highest content of TTC in both the skin and seed extracts. The TSC content was found the highest from skin extract in the ripe stage. The two most common phytosterols found were stig masterol and $\beta$-sitosterol. The stig masterol content was found the highest in the skin extract of the immature, while $\beta$-sitosterol was found in the seed extract of the ripe fruits. This work indicated that the skin and seed of wild grape fruits might be new sources of phytosterol.
\end{abstract}

Keywords: Wild grape, Phytochemical, Phytosterol, Spectrophotometric assay.

\section{INTRODUCTION}

Phytochemicals are secondary metabolites that are non-nutritive, naturally occurring, and biologically active compounds and found in the plant kingdom ${ }^{1}$. Phytochemicals enrich the biological activity potential, including antiinflammation, anti-cancer, antimicrobial, and antioxidant. There are more than a thousand known phytochemicals ${ }^{2}$. Phytosterols are one group of triterpenoid and pervasive in plants. Generally, their structures look like to cholesterol, but side chain has differed in the alkyl position. Among more than 200 different compounds of phytosterol, $\beta$-sitosterol, stigmasterol, and campesterol are predominate types in higher plants and human diets. The several of vegetable oil, nuts, fruit, berries, grapes, and cereals are important sources of the plant sterols. Wild grape is a potent source of antioxidants and anti-bacterials from their

This is an 2 Open Access article licensed under a Creative Commons Attribution-NonCommercial-ShareAlike 4.0 International License (https://creativecommons.org/licenses/by-nc-sa/4.0/ ), which permits unrestricted NonCommercial use, distribution and reproduction in any medium, provided the original work is properly cited. 
polyphenol compounds: flavonoids and phenolic acids $^{3,4}$. According to the phytosterol structures, they should be reduced low-density lipoprotein (LDL)-cholesterol levels in body. Cholesterol was reduced of approximately $10 \%$ by consumption phytosterol of $2 \mathrm{~g} / \mathrm{day}^{5}$. Ruggiro and coworkers ${ }^{6}$ found that the contents of phytosterols were varied in different tissues as well as phenological stage. Millan and coworkers ${ }^{7}$ isolated and evaluated the phytosterol content from cultivated grape and wine by modified a liquid chromatography and ion-trap mass spectrometer. The results found that the highest content of phytosterol was in the grape seed. Wild grape Ampelocissus martinii Planch. is a tropical fruit in the Vitaceae family. It is a traditional herbal ingredient and has been used in folk medicine in Thailand, in which the root is more popular than other plant parts. The shoots and their immature fruit are used as food in Thailand. The stem and fruit of wild grape are similar to cultivated grape with regards to the color and stage of fruit development. With previous works, we found that the wild grape fruits composed of various phytochemicals and each have good biological activities, especially antioxidant and antibacterial activities ${ }^{3,4,8}$. However, information about phytosterol in wild grape has never been reported. In this study, we focused on screening phytosterol in the skin and seed of different growth stages of wild grape fruit extracts. Quantification of the total triterpenoid content and total sterol content by spectrophotometric assay was performed. Finally, some free sterols without derivatization step were also studied using HPLC.

\section{MATERIALS AND METHODS}

\section{Chemicals for analysis}

$\beta$-sitosterol, stig masterol, ergosterol, and cholesterol standards were purchased from Across Organics (New Jersey, USA). The organic solvents, methanol, ethanol, hexane, isopropanol, percholic acid, ursoilc acid, and hydrochloric acid, were obtained from Sigma-Aldrich (USA). Other chemicals, acetic acid, sulfuric acid, vanillin, and potassium hydroxide were purchased from Sigma-Aldrich (USA). The HPLC grade of acetonitrile and methanol were used as mobile phase (Merck, Germany). The other chemicals as well as solvents of analytical grade used were not further purifying.

\section{Sample preparation}

Raw materials of wild grape fruits were collected from Roi-Et Province, Northeastern Thailand from August to September, 2016 and categorized by their fruit colors into immature (green), mature (red), and ripe (black). The skin and seeds of fruits were separated and processed to dry by oven at $60^{\circ} \mathrm{C}$ for 8 hours. The dried samples were prepared into a fine powder by a mortar and kept in sealed plastic bags until further analysis.

\section{Extraction of sample}

The samples of wild grape were extracted with an orbital shaker by modification of the Hara and Radin method $^{9}$. Samples were mixed with 150 $\mathrm{mL}$ of $\mathrm{n}$-hexane:IPA (3:2 v/v). The extract was filtered via filter paper (Whatman No. 1). The debris was re-extracted twice with $150 \mathrm{~mL}$ of the same solvent and then pooled together with the first time extraction. To obtain the biphasic system, $200 \mathrm{~mL}$ of $6.67 \% \mathrm{Na}_{2} \mathrm{SO}_{4}$ in water was added to the combined filtered solution. After gentle mixing, the mixture was allowed at $4{ }^{\circ} \mathrm{C}$ to give phase separation. The lipid appeared in upper organic phase was then dried by evaporation and kept under nitrogen in the dark at $-20^{\circ} \mathrm{C}$ until use.

\section{Investigation of total triterpenoid content (TTC)}

The TTC was investigated using the $\mathrm{Ni}$ method $^{10}$ with some modifications. Briefly, $0.3 \mathrm{~mL}$ of each extract were contained in a tube and heated at $100{ }^{\circ} \mathrm{C}$ in a water bath to dryness. Then added of $0.05 \mathrm{~mL}$ vanillin-acetic acid solution (5:95, w/v) and $0.8 \mathrm{~mL}$ perchloric acid and immersed in a water bath at $60^{\circ} \mathrm{C}$ for 15 minutes. before moving into an ice-water bath. Finally, the prepared solution was mixed with $5 \mathrm{~mL}$ acetic acid and left at room temperature about 15 minutes. The mixture solution and blank as a reference was measured their absorbance by a spectrophotometer at $548 \mathrm{~nm}$. Results are expressed as mg ursolic acid equivalent $(\mathrm{UrE}) / 100 \mathrm{~g} \mathrm{DW}$.

\section{Investigation of total sterol content (TSC)}

The TSC was investigated followed by the Liebermann-Burchard (LB) colorimetric method ${ }^{11}$ with minor modifications. Cholesterol was used as the standard. Firstly, $50 \mu \mathrm{L}$ concentrated $\mathrm{H}_{2} \mathrm{SO}_{4}$ was mixed with $2 \mathrm{~mL}$ acetic anhydride to obtain the LB color reagent. Then, $1 \mathrm{~mL}$ of sample extract in 
chloroform was added to the LB color reagent, stirred for 1 minutes. and kept at room temperature for 13 minutes. The mixture solution was measured absorbance using a spectrophotometer at $650 \mathrm{~nm}$. Results are expressed as $\mathrm{mg}$ cholesterol equivalent (ChE)/100 g DW.

\section{Analysis of sterol using high performance liquid chromatography (HPLC) \\ Sample treatment}

Firstly, the organic phase extracts were evaporated until dryness. The dryness was added with $5 \mathrm{~mL}$ of water to reconstitute solution before adding $5 \mathrm{~mL}$ of $37 \% \mathrm{HCl}$ with heating at $80^{\circ} \mathrm{C}$ for 2 hours. The solution was shaken vigorously every 30 minutes. The samples were stand at room temperature to cool. After that, the solution was mixed with $10 \mathrm{~mL}$ chloroform-methanol $(1: 1, \mathrm{v} / \mathrm{v})$ for free sterol extraction. To separate the solution layer, the solution was vortex-mixed and centrifuged at $3000 \mathrm{rpm}$ for 5 minutes. at $4{ }^{\circ} \mathrm{C}$. Each organic at lower layer was collected and taken for evaporation under a gentle stream of nitrogen to dryness. The dry sample was dissolved in water and mixed with ethanolic solution in $2 \mathrm{M} \mathrm{KOH}$ at $80^{\circ} \mathrm{C}$ for 1 hours for sponification. After cooling, the extracts were then secondary extracted by the same solvent and procedure to obtain the lower organic layer again. They were then dried and reconstituted in $250 \mu \mathrm{L}$ of acetonitrile. Before analysis by HPLC, the extracts were centrifuged to receive solution without contaminant.

\section{Instrumental condition}

Chromatographic separations were performed on an HPLC using the reverse-phase with a C18 column $(2.1 \mathrm{~mm} \times 250 \mathrm{~mm}, 5 \mu \mathrm{m})$. The acetonitrile and water mixture system was used as mobile phase with the isocratic mode of flow rate. The column temperature was adjusted at $35{ }^{\circ} \mathrm{C}$ during the whole run and used $20 \mu \mathrm{L}$ injection volume. The diode array detector was operated at $205 \mathrm{~nm}$.

\section{Statistical analysis}

The data were obtained from triplicate and revealed as means \pm SD. The SPSS ver. 19 for Windows was used for data analysis. The means significances were compared at $p<0.05$ using one-way analysis of variance.

\section{RESULTS AND DISCUSSION}

\section{Total triterpenoid content}

The mature seed showed a higher total triterpenoid content than the other tissues (Fig. 1). There was $1.392 \pm 0.157 \mathrm{mg} \mathrm{UrE} / 100 \mathrm{~g} \mathrm{DW}$, which indicates a significant difference when compared with the immature and ripe stages. The result indicates that the ripe skin extract showed the lowest total triterpenoid content of $0.852 \pm 0.009$ mg UrE/100 g DW.

Figure 1 indicates that the triterpenoid content of wild grape fruit alters during fruit

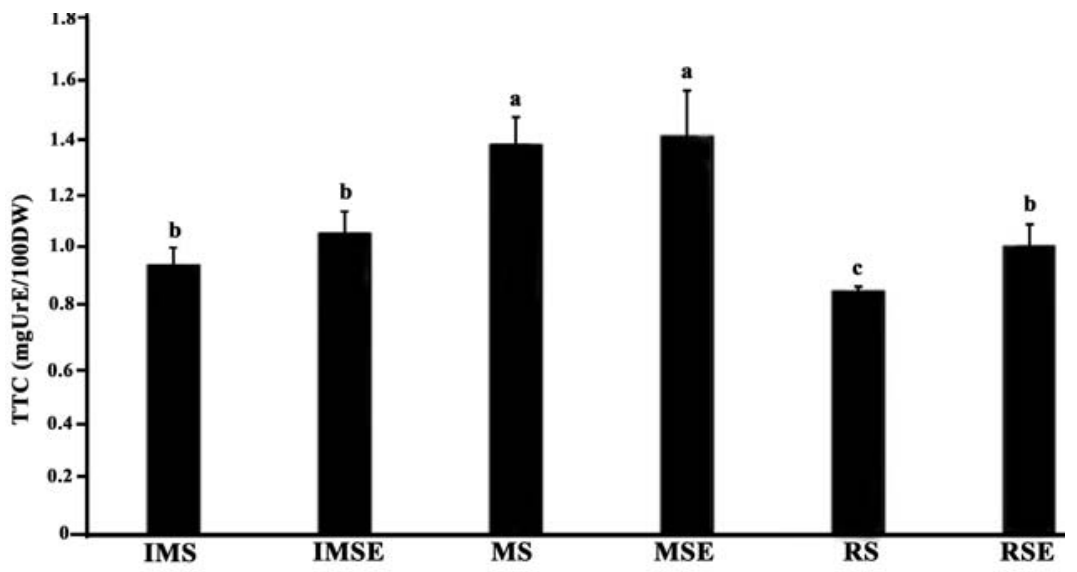

Fig. 1. Total triterpeniod content of different growth stages of wild grape fruits extracts; IMS (immature skin), IMSE (immature seed), MS (mature skin), MSE (mature seed), RS (ripe skin), RSE (ripe seed). Different letters indicated significantly different at $p<0.05$ of means 
development; with an early deposition of high levels that subsequently decreases during ripening as this stage has the termination of oleanolic acid biosynthesis that may result in the modulation of the mechanical toughness of the cuticle that typically appears in numerous fruit ${ }^{12}$. Indeed, triterpenoids are another group of plant secondary metabolites, and the pharmaceutical and physiological activities of triterpenoids are diverse and important and include antidiabetic, anti-HIV, and antioxidant properties $^{13}$. Triterpenoids contained triterpene acids, such as ursolic acid, oleanolic acid, and triterpene alcohol ${ }^{12}$. Therefore, this plant could be important pharmaceutically due to its total terpenoid contents.

\section{Total sterol content}

The total sterol contents of different growth stages of wild grape fruits' skin and seed extracts are presented in Fig. 2. The result indicated that the highest total sterol levels were obtained from the ripe skin (109.483 $\pm 3.836 \mathrm{mg}$ ChE/100 g DW), mature seed $(99.702 \pm 1.562 \mathrm{mg} \mathrm{ChE} / 100 \mathrm{~g} \mathrm{DW})$, and immature skin $(71.485 \pm 1.367 \mathrm{mg} \mathrm{ChE/100} \mathrm{g} \mathrm{DW).}$ The lowest total sterol level was found in the mature skin $(23.923 \pm 7.894 \mathrm{mg} \mathrm{ChE/100} \mathrm{g} \mathrm{DW).} \mathrm{It} \mathrm{can} \mathrm{be}$ observed that the skin of the immature and ripe stages had higher total sterol contents than the seed tissue, while the skin of the mature stage had a lower content than the seed. This report contrasts with the phytosterol content found in cultivar grapes. The skins of the grape had decreased phytosterols levels in the last stage of maturity or during the transition from pre-véraison to véraison ${ }^{12,14}$. It is well known that phytosterols are involved the function of cell membrane including membrane fluidity and permeability regulations and membrane-associated metabolic processes ${ }^{15}$. The excessive cell division and differentiation in the early stage of ripening is a main reason on biosynthesis of compounds such as phytosterol for controlling membrane fluidity ${ }^{16}$. Moreover, sterol biosynthesis was stopped in the last ripening stage due to the end of enzymatic activity, and those of phytosterols were changed to other sterol forms or to stanol ${ }^{14}$.

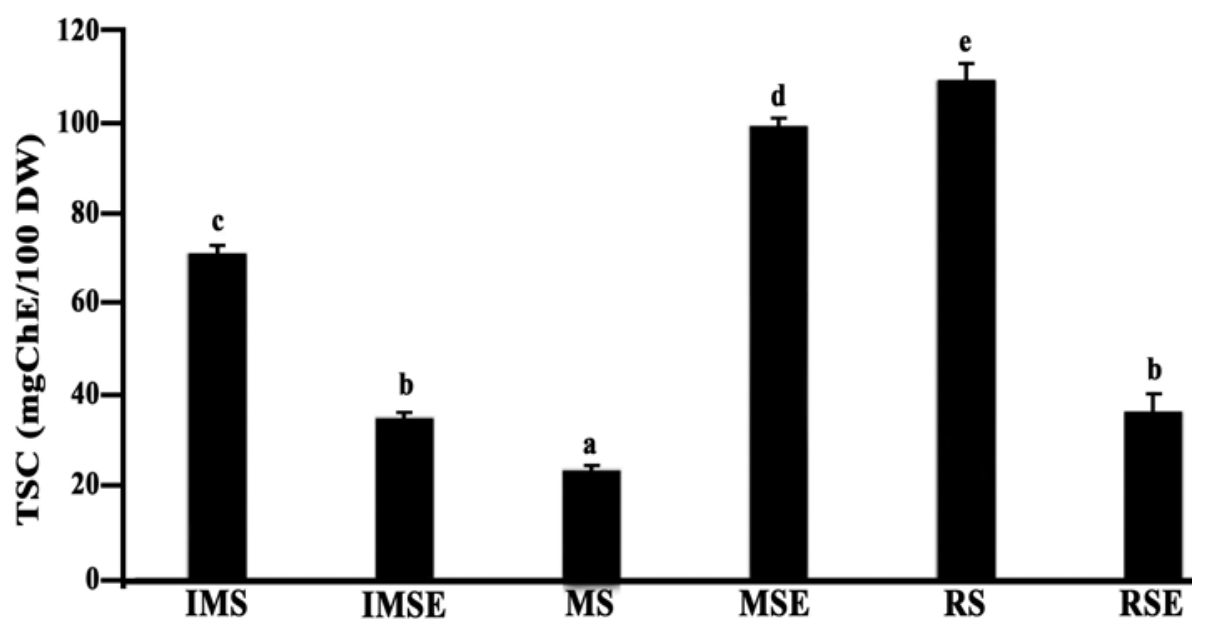

Fig. 2. Total sterol content of different growth stages of wild grape fruits' skin and seed extracts. Different letters indicate means significantly different at $p<0.05$

\section{Contents of free sterol}

Free phytosterols such as stigmasterol and $\beta$-sitosterol, were analyzed using the HPLC technique without derivatization step. This method was simple and avoided thermal conditions, like the GC method, so analyzed samples were not degraded or oxidized to other forms. The reliability of the present study was confirmed by the data shown in Table 1. The coefficient of determination values of sterol were in the range 0.9989-1.000. Moreover, the recovery values were in the range $84-114 \%$. Fig. 3 shows the chromatogram of the 
sterol standard and crude extract of different wild grape tissues. The chromatograms of all wild grape extracts did not have peak number. 1 and 2, which were ergosterol and cholesterol. This suggested that ergosterol can be classified as a yeast sterol, while cholesterol is an animal sterol ${ }^{16}$. The contents of free sterol; stigma sterol and $\beta$-sitosterol, are shown in Table 2. $\beta$-sitosterol was a main compound found in all wild grape stages. High $\beta$-sitosterol contents found in the mature seed, immature skin, and ripe skin were 198.418, 171.538 \pm 0.001 , and $162.095 \pm 0.001 \mathrm{mg} / 100 \mathrm{gDW}$, respectively. The results showed that all extracts could be found the sterol. Exactly, the sterol is indispensable compounds in plasma membranes structure. Moreover, sterols are converted to steroidal hormones in eukaryotes, mammals, insects and higher plants ${ }^{17}$.

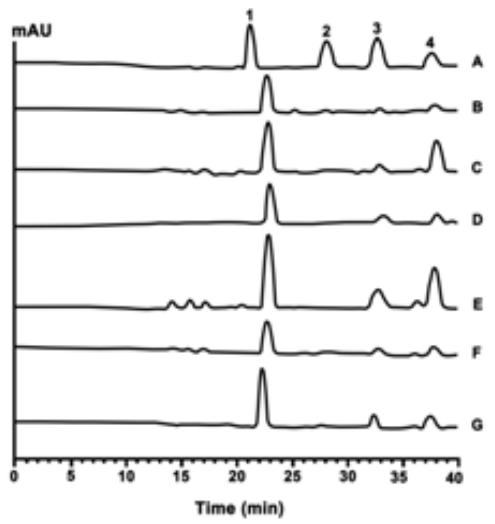

Fig. 3. HPLC chromatogram of sterol standard and wild grape extracts detected by DAD at $205 \mathrm{~nm}$.

The letter on each chromatogram represents sterol standard (A), IMS (B), IMSE (C), MS (D), MSE (E),

RS (F), and RSE (G). The number on the top peak represents ergosterol (1), cholesterol (2), stigmasterol (3), and $\beta$-sitosterol (4).

Table 1: HPLC data of sterol standards

\begin{tabular}{lccccc}
\hline Steros & Calibration curve & $\begin{array}{c}\text { Determination } \\
\text { coefficient }\left(\mathrm{R}^{2}\right)\end{array}$ & $\begin{array}{c}\text { LOD } \\
(\mathrm{mg} / 100 \mathrm{~g})\end{array}$ & $\begin{array}{c}\text { LOQ } \\
(\mathrm{mg} / 100 \mathrm{~g})\end{array}$ & \% Recovery \\
\hline Ergosterol & $\mathrm{y}=9885.7 \mathrm{x}+11961$ & 0.9989 & 0.031 & 0.105 & $114.102 \pm 0.015$ \\
Cholesterol & $\mathrm{y}=8636.2 \mathrm{x}+907.33$ & 0.9990 & 0.027 & 0.091 & $96.798 \pm 0.001$ \\
Stigmasterol & $\mathrm{y}=10184 \mathrm{x}+1239.5$ & 1.0000 & 0.016 & 0.052 & $84.000 \pm 0.003$ \\
$\beta$-sitosterol & $\mathrm{y}=6513 \mathrm{x}-1988.7$ & 0.9993 & 0.026 & 0.085 & $97.625 \pm 0.002$ \\
\hline
\end{tabular}

Table 2: Composition and sterol content of wild grape extracts analyzed by HPLC

\begin{tabular}{lcccccc}
\hline & $\begin{array}{c}\text { Stig masterol } \\
\text { mg/100g DW }\end{array}$ & SD & \%CV & $\begin{array}{c}\beta \text {-sitosterol } \\
\text { mg/100g DW }\end{array}$ & SD & $\%$ CV \\
\hline Immature (skin) & $135.409^{\mathrm{a}}$ & 0.001 & 0.000 & $171.538^{\mathrm{a}}$ & 0.001 & 0.001 \\
Immature (seed) & $3.809^{\mathrm{b}}$ & 0.000 & 0.007 & $46.475^{\mathrm{b}}$ & 0.000 & 0.001 \\
Mature (skin) & $20.856^{\mathrm{c}}$ & 0.003 & 0.013 & $79.460^{\mathrm{c}}$ & 0.002 & 0.003 \\
Mature (seed) & $69.462^{\mathrm{d}}$ & 0.001 & 0.001 & $198.418^{\mathrm{d}}$ & 0.000 & 0.000 \\
Ripe (skin) & $22.636^{\mathrm{e}}$ & 0.000 & 0.002 & $162.095^{\mathrm{e}}$ & 0.001 & 0.000 \\
Ripe (seed) & $4.256^{\mathrm{f}}$ & 0.000 & 0.007 & $14.353^{\mathrm{f}}$ & 0.000 & 0.002 \\
\hline
\end{tabular}

Different letters in the same column represent signicant differences at $p<0.05$ of means.

\section{CONCLUSION}

The mature stages of both wild grape skin and seed accumulated high total triterpenoid contents. When considering the skin extract, the total sterol contents had rapidly decreased by the mature stage and increased again by the end of the ripening stage. This is in contrast to the accumulation of sterol in the seed tissue, which increased rapidly by the mature stage and had 
decreased rapidly by the end of the ripening stage. This is the first report of the quantification of phytosterol from wild grape Ampelocissus martinii Planch, which gave different results from previous report of cultivated grape. This work indicated that the skin and seeds of wild grape fruits might be important sources of phytosterol and should be further studied to obtain more information, especially biological activities.

\section{ACKNOWLEDGENENT}

The authors would like to thank the Faculty of Science and Mahasarakham University, Thailand for financial support of this work. Moreover, we would like to thank the Center of Excellence for Innovation in Chemistry (PERCH-CIC), Commission on Higher Education, Ministry of Education, Thailand for partial financial support.

\section{REFERENCES}

1. Jong, A.; Plat, J.; Mensink, R. P. J. Nutr. Biochem., 2003, 14, 362.

2. Cai, R.; Hettiarachchy, N. S.; Jalaluddin, M. J. Agric. Food. Chem., 2003, 51, 1623.

3. Boonsod, Y.; Sangdee, A.; Srihanam, P. Br. J. Pharm. Res., 2014, 4, 23.

4. Jirum, J.; Sangdee, A.; Srihanam, P. Int. J. Res. Ayurveda Pharm., 2013, 4, 337.

5. Bard, J. M.; Paillard, F.; Lecerf, J. M. Diabetes Metab., 2015, 41, 69.

6. Ruggiro, A.; Vitalini, S.; Burlini, N.; Bernasconi, S.; Iriti, M. Food Chem., 2013, 41, 3473.

7. Millan, L.; Sampedro, M. C.; Sanchez, A.; Goicolea, M. A. J. Food Comp. Anal., 2015, 42, 171.

8. Wongnarat, C.; Srihanam, P. Int. J. Appl. Chem., 2016, 12, 337.

9. Carreno, M.M.; Knol, D.; Janssen, H. G. J. Chromatogr. A., 2016, 1428, 316.

10. Ni, Q. X.; Xu, G. Z.; Wang, Z. Q.; Gao, Q.X.;
Wang, S.; Zhang, Y.Z. Int. J. Mol. Sci., 2012 , 13, 2249.

11. Kim, E. Clin. Chem., 1969, 15, 1171.

12. Pensec, F.; Paczkowski, C.; Grabarczyk, M.; Wozniak, A.; Melanie, B. G.; Bertsch, C.; Chong, J.; Szakiel, A. J. Agric. Food Chem., 2014, 62, 7998.

13. Beieth, A.; Santos, A. R.; Calixto, J. B.; Hess, S. C.; Messma, I.; Ferrari, F.; Yunes, R. A.; Panta Med., 1999, 65, 50.

14. Le Fur, Y.; Hory, C.; Bard, M. H.; Olsson, A. Vitis., 1994, 33, 127.

15. Trautwein, E. A.; Demonty, I. DOSSIER, OCL., 2007, 14, 259.

16. Bouali, I.; Trabelsi, H.; Herchi, W.; Martine, L.; Albouchi, A.; Bouzaien, G.; Sifi. S.; Boukhchina, S.; Berdeaux, O. Food Chem., 2014, 164, 309.

17. Ohyama, K.; Suzuki, M.; Kikuchi, J.; Saito, K.; Muranaka, T. Proc. Natl. Acad. Sci. USA., 2009, 106, 725. 